\title{
Prediction of Hardness in Friction Stir Processing by Artificial Neural Networks
}

\author{
Kartikeya Bector*, Ravi Butola *, Ranganath M. Singari*, S L Bhandarkar** and Kamal Pathak*** \\ *Department of Mechanical Engineering, Delhi Technological University, India \\ **Board of Technical Education, Muni Maya Ram Marg, Pitampura, India \\ ***Delhi Technological University, Delhi, India \\ Corresponding Author: ravibutola33855@gmail.com
}

\begin{abstract}
This research focuses on the use of Artificial Neural Network (ANN) for the prediction of the microhardness of friction stir processed aluminium based metal matrix composite (AA6061+A12O3). Different specimens were obtained by using rotating speeds of $1100,1210,1320$ and $1430 \mathrm{rpm}$ and travelling speeds of 36, 48, 60,72 $\mathrm{mm} / \mathrm{min}$. The microhardness value (HV) of the processed surface of each of the samples was measured and the data collected from the specimens was used as learning data for ANN. Higher rotational speed and lower transversal speeds resulted in higher hardness value since processing at higher tool rotational speed causes high material flow and good resistance to the tool pin profile. A uniform increase in microhardness was observed up to 1320 RPM and a subsequent decrease on any further increments of tool rotational speed. Subsequently, the highest values of microhardness were observed with a square mandrel at $1320 \mathrm{RPM}$ and $36 \mathrm{~mm} / \mathrm{min}$. The calculated results were satisfactorily compliant with the measured data and the ANN model was successful in predicting the microhardness.
\end{abstract}

Keywords: Artificial neural network; Friction stir processing; Hardness; Tool pin profile.

\section{INTRODUCTION}

Friction Stir Processing is a surface modification and fabrication technique which has triumphed over other such surface alteration processes due to its solid-state processing. Spearheaded by Mishra et al. (2003), FSP has emerged to be more successful over techniques like stir casting (Sharma et al., 2017), laser surface engineering (Pantelis et al., 1995), selective laser melting (Zhou et al., 2018) etc. Over the years, FSP has been used extensively to fabricate unique sets of really fine, homogeneous alloys which are not only stronger but also sustainable.

FSP is commonly used for the processing of metal alloys like those of aluminium and magnesium that are lightweight and flexible. FSP renders certain desirable properties to them, compensating for their lack of strength and hardness and making them suitable for further processing (Butola et al., 2019). The outcomes of using FSP on different Al, Mg and steel alloys were studied by Chaudhary et al. (2018). The distinct characteristics of FSPed composites were noted as the process was performed at various angles and speeds. Using B4C nanoparticles as reinforcement for the fabrication of the surface composites of AA7075-T6 (Butola, Chandra, et al., 2021; Butola, Murtaza, et al., 2020b) and AA6063 (Bector, Singh, et al., 2021) alloys has been examined in recent years. Butola et al. (Butola, Tyagi, et al., 2021) studied the effect of processing, reinforcements and tool rotation speed on the mechanical and tribological properties of FSPed AA7075/SiC composite. 
The introduction of Artificial Neural Networks (ANN), has made the construction of complex prediction models possible and also helped to solve problems pertaining to the prediction of alloy properties before they are manufactured by considering multiple variables simultaneously (Bector, Tripathi, et al., 2021). Shojaeefard et al. (2015) used ANN and FEM to establish the association of the tool parameters (pin and shoulder diameter) with the weld region values of HAZ, thermal, and strain. ANN and RSM were used by Jayaraman et al. (2008) for the prediction of the tensile strength of A356 alloy, where ANN was found to be more precise. António et al. (2008) considered cutting speed, feed rate, type of insert of the tool, and type of workpiece material for developing an evolution-learning based ANN for the turning of polyetheretherketone (PEEK) composites and predict complex mechanical and tribological behaviour.

Metal matrix composites are an upcoming and promising field in India. Mitra \& Mahajan (1995) analysed the discontinuously reinforced MMCs and concluded that electronically bonded composites having high metal character exhibit stronger interfacial bonding, leading to improved mechanical properties. Aluminium alloy is a material choice for marine frames, pipelines, storage tanks and aircraft industry and AA6061 is commonly used in these areas. Following the better corrosion resistance and high strength-weight ratio, AA6061 is being widely preferred in the industry, especially in aerospace, marine and automotive industries. In this study, AA6061 was reinforced with A12O3 and hardness tests were performed. On that basis, an ANN was modelled to aid in the design process, efficiency and cost-effectiveness.

\section{EXPERIMENTAL PROCEDURE}

\section{Materials}

AA6061 was used as the base metal following its excellent welding characteristics and strength that it possesses compared to the high strength aluminium and copper alloys (Coyal et al., 2020). Apart from this, it is chosen due to its easy market availability, wide applications and economical efficiency. The microhardness of the as-cast material before FSP was $48 \mathrm{HV}$. A $160 \mathrm{~mm}$ length groove, $2 \mathrm{~mm}$ wide and $3.5 \mathrm{~mm}$ deep (Fig. 1), was made in the workpiece for the incorporation of the reinforcement particles. The pin-profiles were manufactured from H13 tool steel (Butola et al. 2020a), which is a hot worked Cr-Mo steel. Since it can undergo various cycles of cooling and heating during the hot working of the tool while resisting thermal fatigue cracking, it is widely used for cold work and hot work tooling applications.

\section{Design of Experiment}

The experiment was designed according to the need of the ANN model using the Minitab software (Lauro et al., 2016). It was found that a minimum of 16 experiments ought to be conducted to ensure a reliable prediction. The parameters decided for the processing were tool rotational speed, travelling speed and tool pin profile (Salari et al., 2014). Four sets of each of these parameters were considered to improve the reliability of the experiments (Table 1). Taguchi was used for the Design of Experiment using L16 orthogonal array. A capping pass was done using a pinless tool to conceal

the grooves of the reinforcement (Butola et al. 2019). After that, the MMC specimens were numbered as from 1 to 16. Each specimen was assigned a particular tool pin profile, particular rpm and particular travelling speed at which it was FSPed. The tilt angle was fixed +2 degree for processing while during metal matrix composite formation, it was fixed to 0 degrees. These values 


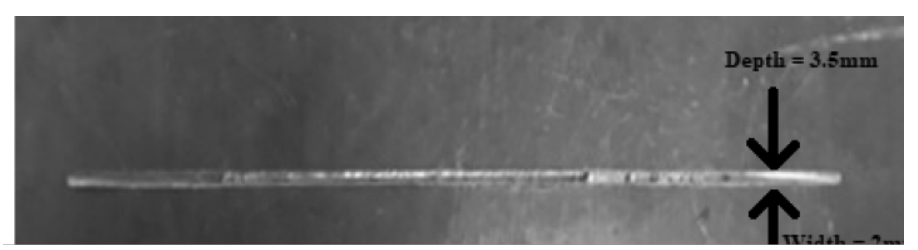

Figure 1: Groove dimensions

have been considered on the basis of the literature review of Butola et al. (2019).

Table 1. Selection of process parameter using Taguchi L16 Orthogonal Array

\begin{tabular}{|l|l|l|l|l|l|}
\hline Processing Parameter & Unit & Level 1 & Level 2 & Level 3 & Level 4 \\
\hline Tool Pin Profile & - & Triangular & Hexagonal & Square & Cylindrical \\
\hline Tool Rotational Speed & Rpm & 1100 & 1210 & 1320 & 1430 \\
\hline Tool Traverse Speed & $\mathrm{mm} / \mathrm{min}$ & 36 & 48 & 60 & 72 \\
\hline
\end{tabular}

\section{Fabrication of Surface Composite}

FSP involves the introduction of a non-consumable tool, which turns at a high rotational speed, slowly onto the surface of the workpiece while a constant power is being applied pivotally to ensure the interaction of the shoulder of the tool with the substrate for abrasion (Li et al., 2019). It is then moved along the substrate in the desired direction of processing. As the tool moves, it plasticizes and heats the material (frictional heat between the interacting tool-shoulder and workpiece), forcing it along the processing line and beneath its back-up rim - here, the material gets compacted and melded due to the severe deformation, before cooling down. The arrangement of the schematics of FSP, along with its apparatus, is illustrated in Fig. 2a and Fig. 2b respectively. Al2O3 was considered as the reinforcement material and a different tool pin profile was used for the fabrication of the AMMC using groove-method (Butola et al., 2019). Srivastava et al. (2019)

determined the optimum
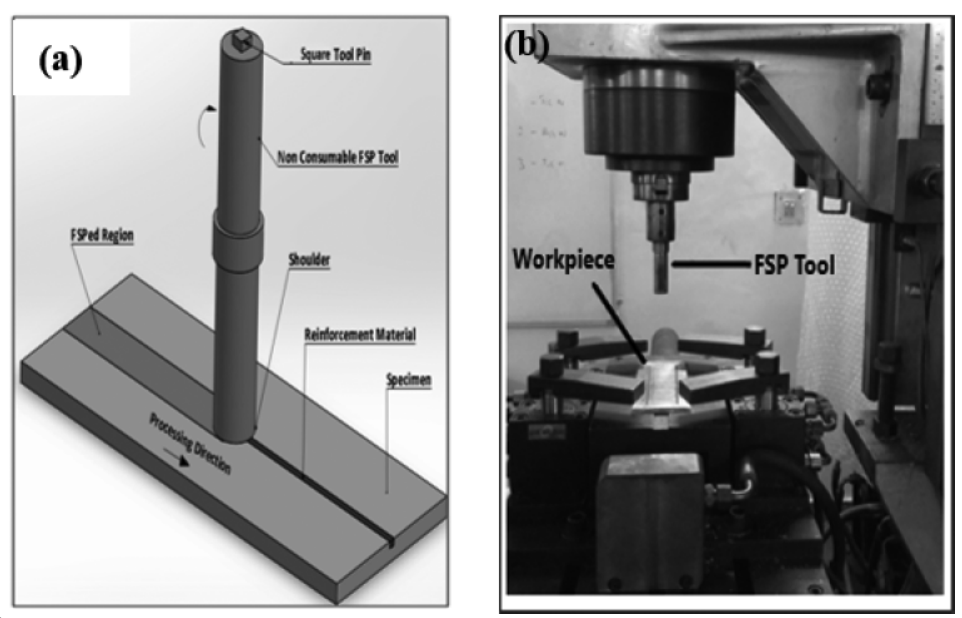

Figure 2. a) Schematic diagram of Friction stir processing b) FSP set up 
values of FSP parameters in the fabrication of AA6063/SiC surface composite using Taguchi. They inferred that the values of microhardness of the composite increased directly in proportion to the tool rotational speed; whereas, an increase in tool traverse speed resulted in an initial increase and subsequent reduction of microhardness

The physical changes occurring at various points of the tool-substrate interface during the traversal due to the different tool profiles are crucial and need to be considered (Bauri et al., 2011). The dimensions and the shape of the tool pin considerably impact the quanta of heat engendered, in addition to the material flow during FSP. Frictional heat is generated at the points where the rotating tool shoulder interacts the workpiece, where it plasticizes the metal at positions immediately adjacent to the pin (in addition to the shoulder generated heat) (McNelley et al., 2008) and pushes it downwards. A wider shoulder diameter leads to more localization of the frictional heat. This movement of the softened metal around the pin results in the weld seam getting joined. Consequently, the second phase particles are better refined, leading to a more stable microstructure. Meshram et al. (2016) observed the impact of threaded tool pin profile and tool rotational speed for the production of a FSW of AA 2014-T6 plate that is free of defects. Because of the relatively larger frictional area, higher levels of heat generation are obtained. The pin profile, hence, is a crucial parameter and is primarily responsible for the regulation of the temperature being generated at the shoulder-substrate interface. A conical pin has been found to result in the least rise in temperature. Butola et al. (2019) investigated three distinct pin profiles and studied their impact on AA7075/SiC, RHA and B4C-reinforced composites. They established a square mandrel resulted in the most homogenous dispersion of particles in the stir zone (which was also observed to be smaller). That is the reason for the consideration of different pin profiles

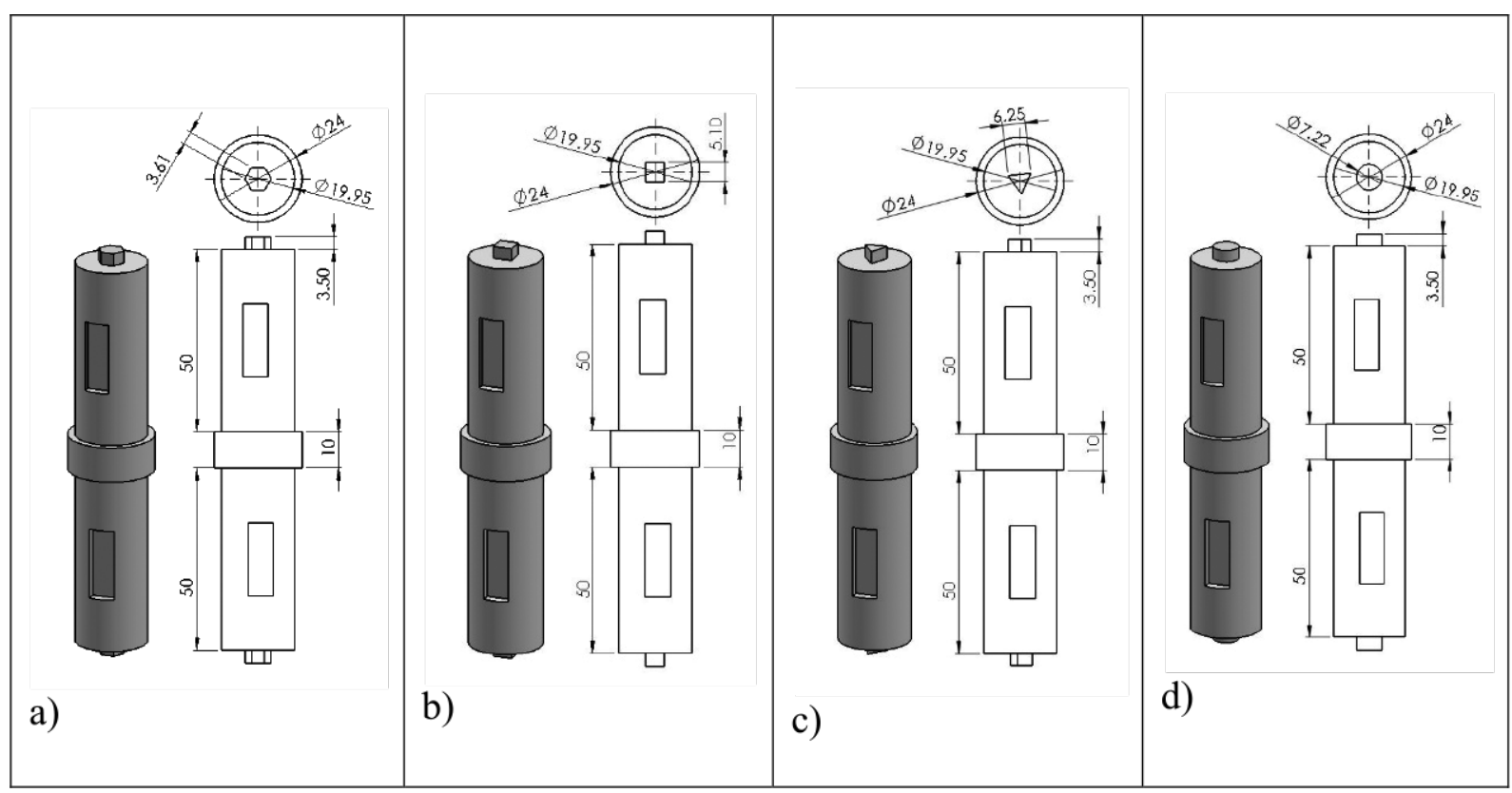

in our study (Fig. 3).

Figure 3. Different tool pin profiles - (a) Hexagonal (b) Square (c) Triangular (d) Cylindrical 


\section{Microhardness Testing}

The Fischer scope HM2000S tester was used for the measurement of the HV value of a sample according to ASTM:E8/E8M-011. The specimen was fixed on the indentation lens and a Vickers (DPH) diamond indenter was pushed into the surface of the material with a penetrator and standard application for hardness was chosen. Then the force was increased to $500 \mathrm{mN}$ from $300 \mathrm{mN}$ along with the creep time being 5 seconds and operating tie being 40 seconds and from the properties taskbar, the HV property was selected for the specimen hardness. The zero point was identified by the machine in a while and then force increases from 0 to $500 \mathrm{mN}$ for 20 seconds. A creep time for 5 seconds was observed and then the force decreased $500 \mathrm{mN}$ to $0 \mathrm{~N}$ in the next 20 seconds. Then a graph along with tabular data was displayed on the screen with variable values of ' $n$ ', where ' $n$ ' is the number of readings for that particular specimen. Similarly, 3 to 4 readings for each specimen were recorded and the specimen was changed. In tandem with the study by Tyagi et al. (2020), the microhardness improved as the tool RPM was increased.

\section{Artificial Neural Network}

A neural system comprises a systematically interwoven cluster of artificial neurons (or nodes) and it forms relationships using the data through a connectivistic approach for calculation. Neural systems are akin to biological systems of neurons - all tasks are performed collectively and simultaneously by the nodes, as opposed to there being a demarcation of subtasks to distinct units. The fundamental component of an ANN is a neuron. Neurons are associated with one another by links termed synapses, and a weight factor is assigned to every synapse. ANNs have three basic layers, namely, input, hidden and output layers. All input factors are present in the input layer. The input datapoints are computed over at least one hidden layer and the final response vector is processed in the last layer. A common learning algorithm is the back propagation algorithm and it is utilized with an ANN which has an input layer with minimum two neurons. A central task in the study of ANNs is the selection of the optimum ANN structure, the activation function and the number of neurons in the hidden layer (through tentation).

MATLAB was utilized to construct a multi-layer feed forward ANN model (Okuyucu et al., 2007). As a direct relationship of the response parameters with the input parameters is not known, target parameters are constructed on a three-layer NN by utilizing information collected from mechanical experiments. The output layer has the number of neurons corresponding to the number of desired response functions (one). The hidden layer neurons ought to be chosen so that the quantity of network unknowns, the weights and biases, doesn't surpass a specific number (here, 192). Pin profile, tool rotational speed and tool traveling speed were taken as the three inputs and the microhardness (HV) values were considered as the output (Fig. 4). Since the tool pin profile is a categorical variable (Bartholomew, 2013), one-hot encoding was done. An ANN, with one hidden layer of 10 neurons, was trained with the Levenberg-Marquardt optimization algorithm (Ahmad et al., 2020). The L-M network training function, the hyperbolic tangent sigmoid as the transfer function for hidden and output layers. and the Mean Square Error (MSE) as the network error function were considered in the model. 


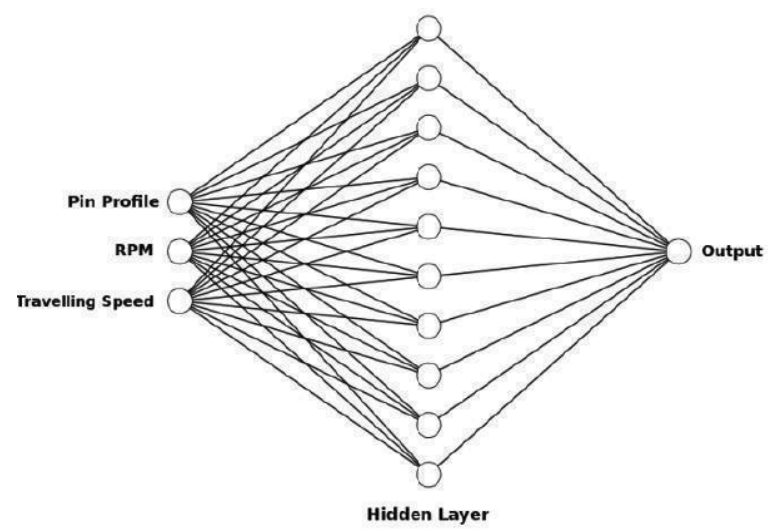

Figure 4. Model of the ANN architecture used

\section{RESULTS AND DISCUSSION}

\section{Microhardness}

The experimental values of microhardness are given in Table 2. It was observed that there was a uniform increase in microhardness across specimens until 1320 RPM. A subsequent increase in RPM led to a decrease in the Vickers microhardness value because of FSP tool wear (Butola et al., 2020). Fig. 5 shows the trend of the experimental values of $\mathrm{HV}$.

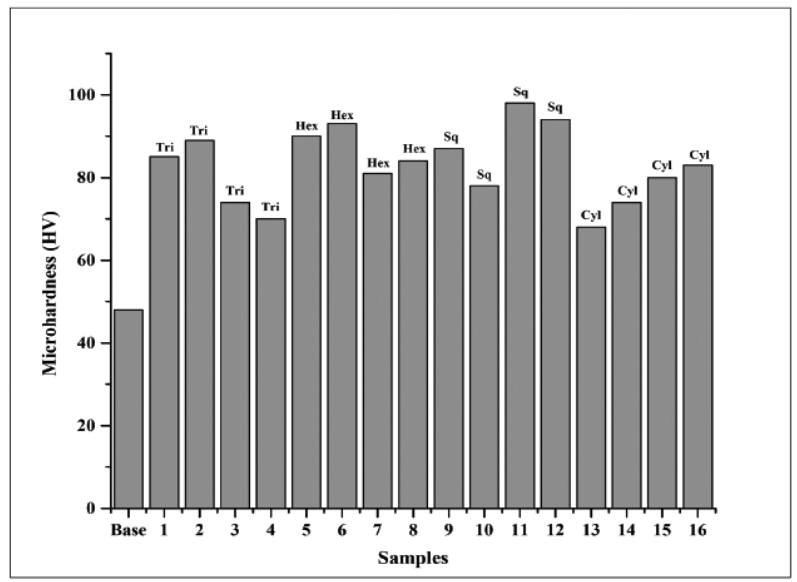

Figure 5. Experimental values of microhardness 
Table 2 All the parameters along with their tested and predicted microhardness (HV)

\begin{tabular}{|c|c|c|c|c|c|}
\hline $\begin{array}{c}\text { Sample } \\
\text { No. }\end{array}$ & $\begin{array}{l}\text { Tool pin } \\
\text { profile }\end{array}$ & $\begin{array}{c}\text { Tool rotational } \\
\text { speed }\end{array}$ & $\begin{array}{c}\text { Travelling } \\
\text { speed }\end{array}$ & Hardness (HV) & Predicted HV \\
\hline 1 & Triangular & 1100 & 36 & 85 & 85 \\
\hline 2 & Triangular & 1210 & 48 & 89 & 89 \\
\hline 3 & Triangular & 1320 & 60 & 74 & 74.02 \\
\hline 4 & Triangular & 1430 & 72 & 70 & 70 \\
\hline 5 & Hexagonal & 1100 & 48 & 90 & 90 \\
\hline 6 & Hexagonal & 1210 & 36 & 93 & 93 \\
\hline 7 & Hexagonal & 1320 & 72 & 81 & 79.75 \\
\hline 8 & Hexagonal & 1430 & 60 & 84 & 84 \\
\hline 9 & Square & 1100 & 60 & 87 & 87 \\
\hline 10 & Square & 1210 & 72 & 78 & 78.03 \\
\hline 11 & Square & 1320 & 36 & 98 & 98 \\
\hline 12 & Square & 1430 & 48 & 94 & 94 \\
\hline 13 & Cylindrical & 1100 & 72 & 68 & 68 \\
\hline 14 & Cylindrical & 1210 & 60 & 74 & 74 \\
\hline 15 & Cylindrical & 1320 & 48 & 80 & 80.001 \\
\hline 16 & Cylindrical & 1430 & 36 & 83 & 83 \\
\hline
\end{tabular}




\section{Artificial neural network}
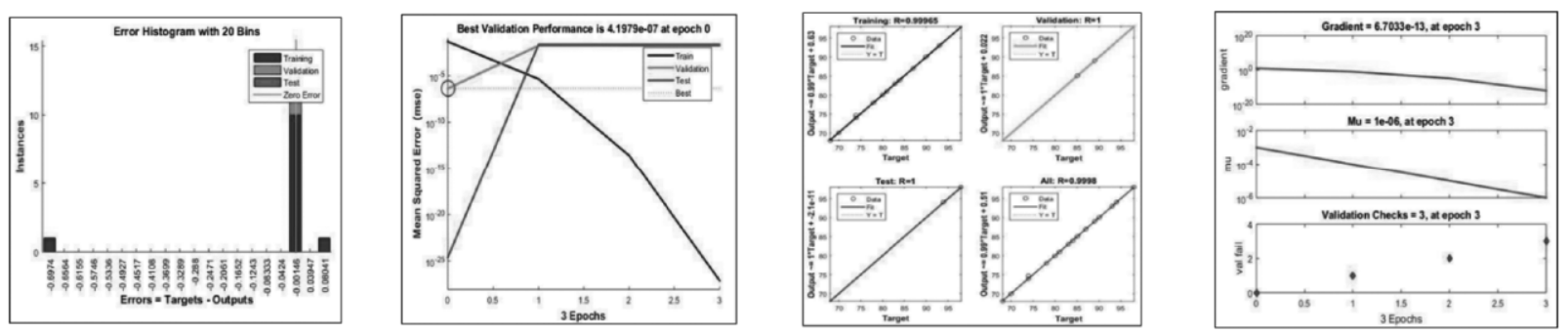

Figure 6. Training plots of ANN for microhardness a) Error histogram plot b) Best validation graph c) Training state graph d) Regression plots

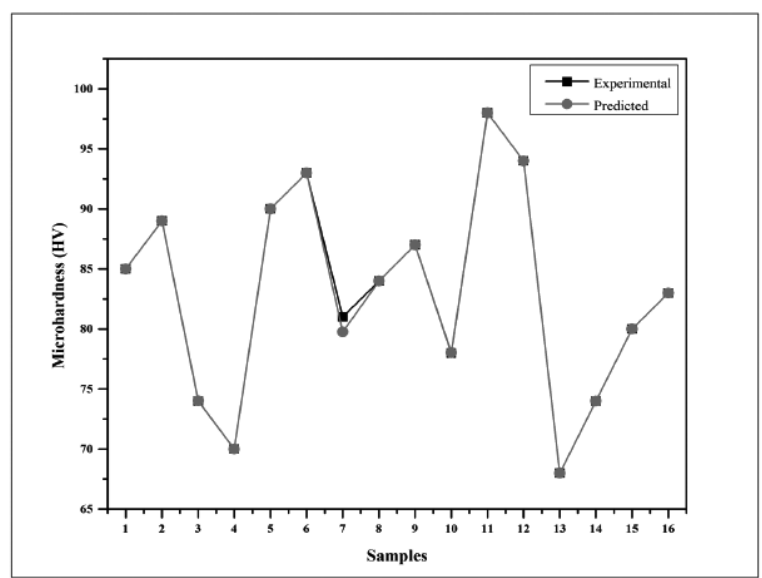

Figure 7. Comparison of experimental and predicted microhardness values for specimens 1-16

The regression plots for the trained model are shown below with their explanations. The Error histogram (Fig. 6a) shows the binned representation of the range of error obtained during various stages of the modelling, viz. Training, testing and validation, with respect to the zero-error line. Training and testing were done to ensure that an optimum model is obtained while avoiding over fitting of the data. Best Validation Graph (Fig. 6b) shows the plot of the Mean Squared Error (MSE) about the three epochs of training done and outlines how the error has changed with subsequent epochs of running the model. MSE is the main parameter that helps us to judge the performance of our model during the training period, as it is a helpful parameter to determine the difference between the predicted and real values, and hence helps to revise the weights and biases matrices of the neural network. Training state data graph (Fig. 6c) shows $\mathrm{mu}$ - control parameter for the training algorithm of the ANN. The choice of mu is directly consequential for the convergence of error. In case of the Levenberg-Marquardt optimization, mu depends on the maximum eigenvalue of the correlation matrix of the input. It is involved in the weight update expression and avoids the issue of attaining a local minimum. Often, the $\mathrm{NN}$ assumes that the minimum error value obtained by it is the global minimum and a further reduction in the value of error may not be feasible. The predictions obtained using the ANN model were found to be very accurate as is visible in the Regression plots (Fig. 6d). These graphs show how a best fit line could be plotted with respect to the data points to help us visually perceive the performance of the ANN model. An overall R-value of 0.9998 was obtained and the predicted HV values are shown in Table 2. Fig. 7 compares the experimentally obtained and the ANN-predicted values of microhardness. 


\section{CONCLUSION}

To determine the impact of tool pin profile, tool traversal speed and tool rotational speed on FSPed composites, the material behaviour was studied by measuring the microhardness profiles in the cross-sections.

- The AA6061+Al2O3 was successfully fabricated using Friction Stir Processing and its microhardness was determined for different Tool Pin Profiles and values of Tool rotational speed and Tool traversal speed.

- Increasing the tool rotational speed and lowering the traversal speed resulted in an increment in the specimens' hardness in all examined scenarios. The increase in hardness may be explained via the improvement in material flow and the resulting increase in resistance against the tool pin profile which leads to FSP tool wear and the subsequent drop in hardness after 1320 RPM. It was further noted that Friction stir processing was the most efficacious in the case of a square pin profile, as the highest values of microhardness were observed here. An RPM of 1320 and a tool traversal speed of $36 \mathrm{~mm} / \mathrm{min}$ proved to be the best combination and yielded the highest microhardness value.

- An Artificial Neural Network was successfully constructed for the modeling of the microhardness of the specimen with respect to the processing parameters and the R-value of 0.9998 was found to be well within the acceptable error limits.

\section{REFERENCES}

Ahmad, S., Singari, R. M., \& Mishra, R. S. (2020). Modelling and optimisation of magnetic abrasive finishing process based on a non-orthogonal array with ANN-GA approach. Transactions of the Institute of Metal Finishing, 98(4), 186-198. https://doi.org/10.1080/00202967.2020.1776966

António, C. A. C., Davim, J. P., \& Lapa, V. (2008). Artificial neural network based on genetic learning for machining of polyetheretherketone composite materials. The International Journal of Advanced Manufacturing Technology, 39(11-12), 1101-1110. https://doi.org/10.1007/s00170-007-1304-5

Bartholomew, D. J. (2013). Categorical Variables (pp. 47-53). https://doi.org/10.1007/978-3-642-39912-1_8

Bauri, R., Yadav, D., \& Suhas, G. (2011). Effect of friction stir processing (FSP) on microstructure and properties of Al-TiC in situ composite. Materials Science and Engineering: A, 528(13-14), 4732-4739. https://doi.org/10.1016/j.msea.2011 .02.085

Bector, K., Singh, M., Pandey, D., Butola, R., \& Singari, R. M. (2021). Study of residual stresses in multi-pass frictionstir processed surface composites. Advances in Materials and Processing Technologies, 1-15. https:// doi.org/10.1080/2374068X.2021.1939983

Bector, K., Tripathi, A., Pandey, D., Butola, R., \& Singari, R. M. (2021). A Review on the Fabrication of Surface Compoites via Friction Stir Processing and Its Modeling Using ANN. In R. M. Singari, K. Mathiyazhagan, \& H. Kumar (Eds.), Advances in Manufacturing and Industrial Engineering. (pp. 1-11). Lecture Notes in Mechanical Engineering, Springer, Singapore. https://doi.org/10.1007/978-981-15-8542-5_1

Butola, R., Murtaza, Q., \& Singari, R. M. (2019). Advances in Computational Methods in Manufacturing. In Lecture Notes on Multidisciplinary Industrial Engineering (pp. 337-348).

Butola, Ravi, Chandra, P., Bector, K., \& Singari, R. M. (2021). Fabrication and multi-objective optimization of friction stir processed aluminium based surface composites using Taguchi approach. Surface Topography: Metrology and Properties. http://iopscience.iop.org/article/10.1088/2051-672X/ac0ba3

Butola, Ravi, Malhotra,A., Yadav, M., Singari, R., Murtaza, Q., \& Chandra, P. (2019). Experimental Studies on Mechancal Properties of Metal Matrix Composites Reinforced with Natural Fibres Ashes. SAE Technical Papers, 2019-April(April), 1-11. https://doi.org/10.4271/2019-01-1123 
Butola, Ravi, Murtaza, Q., \& Singari, R. M. (2020a). An experimental and simulation validation of residual stress measurement for manufacturing of friction stir processing tool. Indian Journal Of Engineering \& Materials Sciences, 27, 826-836.

Butola, Ravi, Murtaza, Q., \& Singari, R. M. (2020b). Formation of Self-Assembled Monolayer and Characterization of AA7075-T6/B 4 C Nano-ceramic surface composite using Friction Stir Processing. Surface Topography: Metrology and Properties, 8(2), 025030. https://doi.org/10.1088/2051-672X/ab96db

Butola, Ravi, S, R. M., \& Murtaza, Q. (2019). Fabrication and optimization of AA7075 matrix surface composites using Taguchi technique via friction stir processing (FSP). Engineering Research Express, 1(2), 025015. https://doi.org/10.1088/2631-8695/ab4b00

Butola, Ravi, Singari, R. M., \& Murtaza, Q. (2020). Mechanical and wear behaviour of Friction stir processed surface composite through Self-Assembled Monolayer Technique. Surface Topography: Metrology and Properties, 8(4), 045007. https://doi.org/10.1088/2051-672X/abbcb8

Butola, Ravi, Tyagi, L., Singari, R. M., Murtaza, Q., Kumar, H., \& Nayak, D. (2021). Mechanical and wear performance of $\mathrm{Al} / \mathrm{SiC}$ surface composite prepared through friction stir processing. Materials Research Express, 8(1), 016520. https://doi.org/10.1088/2053-1591/abd89d

Chaudhary, A., Kumar Dev, A., Goel, A., Butola, R., \& Ranganath, M. S. (2018). The Mechanical Properties of Different alloys in friction stir processing: A Review. Materials Today: Proceedings, 5(2), 5553-5562. https://doi.org/10.1016/j.matpr.2017.12.146

Coyal, A., Yuvaraj, N., Butola, R., \& Tyagi, L. (2020). An experimental analysis of tensile, hardness and wear properties of aluminium metal matrix composite through stir casting process. SN Applied Sciences, 2(5), 1-10. https://doi.org/10.1007/s42452-020-2657-8

Jayaraman, M., Sivasubramanian, R., Balasubramanian, V., \& Lakshminarayanan, A. K. (2008). Prediction of Tensile Strength of Friction Stir Welded A356 Cast Aluminium Alloy Using Response Surface Methodology and Artificial Neural Network. Journal for Manufacturing Science and Production, 9(1-2), 45-60. https://doi.org/10.1515/IJMSP.2008.9.1-2.45

Lauro, C. H., Pereira, R. B. D., Brandão, L. C., \& Davim, J. P. (2016). Design of Experiments - Statistical and Artificial Intelligence Analysis for the Improvement of Machining Processes: A Review (pp. 89-107). https://doi.org/10.1007/978-3-319-23838-8_3

Li, K., Liu, X., \& Zhao, Y. (2019). Research Status and Prospect of Friction Stir Processing Technology. Coatings, 9(2), 129. https://doi.org/10.3390/coatings9020129

McNelley, T. R., Swaminathan, S., \& Su, J. Q. (2008). Recrystallization mechanisms during friction stir welding/processing of aluminum alloys. Scripta Materialia, 58(5), 349-354. https://doi.org/10.1016/ j.scriptamat.2007.09.064

Meshram, S. D., Reddy, G. M., \& Rao, A. V. (2016). Role of Threaded Tool Pin Profile and Rotational Speed on Generation of Defect Free Friction Stir AA 2014 Aluminium Alloy Welds. Defence Science Journal, 66(1), 57. https://doi.org/10.14429/dsj.66.8566

Mishra, R. S., Ma, Z. Y., \& Charit, I. (2003). Friction stir processing: A novel technique for fabrication of surface composite. Materials Science and Engineering A, 341(1-2), 307-310. https:/doi.org/10.1016/S0921-5093(02)00199-5

Mitra, R., \& Mahajan, Y. R. (1995). Interfaces in discontinuously reinforced metal matrix composites: An overview. Bulletin of Materials Science, 18(4), 405-434. https://doi.org/10.1007/BF02749771

Okuyucu, H., Kurt, A., \& Arcaklioglu, E. (2007). Artificial neural network application to the friction stir welding of aluminum plates. Materials \& Design, 28(1), 78-84. https://doi.org/10.1016/j.matdes.2005.06.003 
Mitra, R., \& Mahajan, Y. R. (1995). Interfaces in discontinuously reinforced metal matrix composites: An overview. Bulletin of Materials Science, 18(4), 405-434. https://doi.org/10.1007/BF02749771

Okuyucu, H., Kurt, A., \& Arcaklioglu, E. (2007). Artificial neural network application to the friction stir welding of aluminum plates. Materials \& Design, 28(1), 78-84. https://doi.org/10.1016/j.matdes.2005.06.003

Pantelis, D., Tissandier, A., Manolatos, P. \&, \& Ponthiaux, P. (1995). Formation of wear resistant Al-SiC surface composite by laser melt-particle injection process. Mater. Sci. Technol., 11(3), 299-303.

Salari, E., Jahazi, M., Khodabandeh, A., \& Ghasemi-Nanesa, H. (2014). Influence of tool geometry and rotational speed on mechanical properties and defect formation in friction stir lap welded 5456 aluminum alloy sheets. Materials \& Design, 58, 381-389. https://doi.org/10.1016/j.matdes.2014.02.005

Sharma, V. K., Singh, R. C., \& Chaudhary, R. (2017). Effect of flyash particles with aluminium melt on the wear of aluminium metal matrix composites. Engineering Science and Technology, an International Journal, 20(4), 1318-1323. https://doi.org/10.1016/j.jestch.2017.08.004

Shojaeefard, M. H., Khalkhali, A., Akbari, M., \& Asadi, P. (2015). Investigation of friction stir welding tool parameters using FEM and neural network. Proceedings of the Institution of Mechanical Engineers, Part L: Journal of Materials: Design and Applications, 229(3), 209-217. https://doi.org/10.1177/1464420713509075

Srivastava, M., Siddiquee, A. N., Rathee, S., \& Maheshwari, S. (2019). Optimisation of friction stir processing parameters to fabricate AA6063/SiC surface composites using Taguchi technique. International Journal of Materials and Product Technology, 58(1), 16. https://doi.org/10.1504/ijmpt.2019.10017760

Tyagi, L., Butola, R., \& Jha, A. K. (2020). Mechanical and tribological properties of AA7075-T6 metal matrix composite reinforced with ceramic particles and aloevera ash via Friction stir processing. Materials Research Express, 7(6). https://doi.org/10.1088/2053-1591/ab9c5e

Zhou, Y., Duan, L., Wen, S., Wei, Q., \& Shi, Y. (2018). Enhanced micro-hardness and wear resistance of Al-15Si/TiC fabricated by selective laser melting. Composites Communications, 10, 64-67. https://doi.org/10.1016/j.coco.2018.06.009 